\title{
Correction to: Medical Neglect as a Contributor to Poorly Controlled Asthma in Childhood
}

\author{
Barbara L. Knox ${ }^{1} \cdot$ Francois M. Luyet ${ }^{2,3}$ • Debra Esernio-Jenssen ${ }^{4,5}$ \\ Published online: 19 May 2020 \\ (C) Springer Nature Switzerland AG 2020
}

\section{Correction: Journal of Child \& Adolescent Trauma}

https://doi.org/10.1007/s40653-019-00290-0
The corresponding author has the wrong affiliation. The correct one is written below.

Alaska Child Abuse Response and Evaluation Services The Children's Hospital at Providence, Anchorage, Alaska

The online version of the original article can be found at https://oi.org/ 10.1007/s40653-019-00290-0

Barbara L. Knox

barbara.knox@providence.org

1 Alaska Child Abuse Response and Evaluation Services, The Children's Hospital at Providence, Anchorage, AK, USA

2 University of Wisconsin American Family Children's Hospital, Madison, WI, USA

3 Department of Pediatrics, University of Wisconsin School of Medicine and Public Health, Madison, WI, USA

4 Lehigh Valley Reilly Children's Hospital, Allentown, PA, USA

5 Morsani College of Medicine USF Health, Tampa, FL, USA 